\title{
ABUNDANCES IN J-TYPE CARBON STARS
}

Kazuhiko Utsumi

Department of Astronomy, Faculty of Integrated Arts and

Sciences, Hiroshima University, Hiroshima 730, Japan.

I) Introduction

It has been found by Utsumi (1985a,b) that in J-type carbon stars of $04-5$ and WZ Cas $(09,2 \mathrm{~J} \mathrm{Li})$, abundances of s-process elements with respect to $\mathrm{Fe}$ are nearly normal, while in normal carbon stars of $65-8$, heavy metals are overabundant by factors of 10-100, and rare-earth elements are overabundant by a factor of about 10 .

In the MK system, most J-type stars are classified as 64-5,4-5 stars which show very strong $\mathrm{C}_{2}$ and $\mathrm{CN}$ bands. Yamashita $(1972,1975)$ classified many $\mathrm{C} 7-9$ stars most of which are CS or SC stars. His classification of $67-9 \mathrm{~J}$ stars is mainly based on $\mathrm{C}^{12} \mathrm{C}^{13}(0,1)$ band at $6168 \mathrm{~A}, \mathrm{C}^{13} \mathrm{~N}(4,0)$ band at $6260 \mathrm{~A}$, and LiI $6708 \mathrm{~A}$ line. In most of C7-9 stars, lines of s-process elements are greatly enhanced. It is a question if in all J-type stars abundances of s-process elements are nearly normal or not.

\section{II) Observation}

We tested the classification of J-type stars using the spectra obtained at the Okayama Astrophysical Observatory, in the region between $4400 \mathrm{~A}$ and $6800 \mathrm{~A}$ with a dispersion of about $13.5 \mathrm{~A} / \mathrm{mm}$. Table 1 shows the stars studied together with the spectral type by the Harvard system and by Yamashita, and the $\mathrm{G}^{13}$ index by Yamashita.

From the spectra between $6100 \mathrm{~A}$ and $6300 \mathrm{~A}$, it is found that in all $07-9$ stars it appears as if $\mathrm{C}^{13}$ features are very strong with low dispersions, because $\mathrm{C}_{2}$ and $\mathrm{CN}$ bands are weak, and strong low-excitation atomic lines coinclde in chance with $\mathrm{C}^{13}$ features. Table 2 shows the strong atomic lines which coincide in chance with these molecular bands. It is better to use $C_{2}(1,0)$ bands to find J-type stars.

Table 1

\begin{tabular}{|c|c|c|c|c|c|c|}
\hline Star & Spectral Type & $a^{13}$ & Star & Spect? & ral Type & $c^{13}$ \\
\hline HD 16115 & $\mathrm{R} 3 ; \mathrm{C2}, 3 \mathrm{~J}$ & 4 & R CMi & & $G, 1(\mathrm{~J}) e$ & 4 \\
\hline HD $1955^{\circ}$ & $\mathrm{R} 5: \mathrm{C4}, 5 \mathrm{~J}$ & 5 & FU Mon & & $\mathrm{C} 8,0(\mathrm{~J})$ & 4 \\
\hline UV Cam & $\mathrm{R8} ; \mathrm{C4}, 5 \mathrm{~J}$ & 4 & & & & \\
\hline HD 52432 & R5; $\quad \mathrm{C} 4,5 \mathrm{~J}$ & 5 & WZ Cas & N1p; & $69,2 \mathrm{~J} \mathrm{Li}$ & 4 \\
\hline HD 79319 & $\mathrm{R} 4 ; \mathrm{C4}, 4 \mathrm{~J}$ & 4 & WX Cyg & N3e; & $\mathrm{C9}, 2 \mathrm{~J} \mathrm{L1}$ & 5 \\
\hline HD $16822 ?$ & $\mathrm{R} 5: \mathrm{C} 4,5 \mathrm{~J}$ & 5 & & & & \\
\hline $\begin{array}{l}\text { Y CVn } \\
\text { RY Dra }\end{array}$ & $\begin{array}{l}\mathrm{N} 3 ; \mathrm{C} 5,5 \mathrm{~J} \\
\mathrm{~N} 4 ; \mathrm{C} 4,5 \mathrm{~J}\end{array}$ & $\begin{array}{l}5 \\
5\end{array}$ & $\begin{array}{l}\text { U Hya } \\
\text { RR Her } \\
\text { RS Cyg } \\
\text { U Cyg }\end{array}$ & $\begin{array}{l}\text { N2; } \\
\text { K5ep; } \\
\text { NOpe; } \\
\text { Np; }\end{array}$ & $\begin{array}{l}66,3 \\
68,2 \mathrm{e} \\
68,2 \mathrm{e} \\
68,2 \mathrm{e}\end{array}$ & $\begin{array}{l}3+ \\
3+ \\
4 \\
4\end{array}$ \\
\hline
\end{tabular}




\begin{tabular}{|c|c|c|c|}
\hline Wavelength & Molecular Band & Wavelength & Atomic Line \\
\hline $\begin{array}{l}\text { 6t02 A } \\
6122 \\
6168\end{array}$ & $\begin{array}{l}\mathrm{c}_{12}^{12} \mathrm{c}_{12}^{13}(1,3) \\
\mathrm{c}_{12}^{12} \mathrm{c}_{13}(1,3) \\
\mathrm{c}^{12} \mathrm{C}^{13}(0,2)\end{array}$ & $\begin{array}{l}6102.72 \mathrm{~A} \\
6122.22 \\
6170.34\end{array}$ & $\begin{array}{l}\text { CaI } 3 \\
\text { CaI } 3 \\
\text { VI } 20\end{array}$ \\
\hline $\begin{array}{l}6191 \\
6206 \\
6260\end{array}$ & $\begin{array}{l}\mathrm{c}_{12}^{12} \mathrm{c}^{12}(0,2) \\
\mathrm{c}_{13} \mathrm{~N}(4,0) \mathrm{R}_{1} \\
\mathrm{c}^{13} \mathrm{~N}(4,0) \mathrm{R}_{1}\end{array}$ & \begin{tabular}{l}
6162.18 \\
6191.73 \\
\hdashline 6258.96 \\
6258.62 \\
6261.23
\end{tabular} & \begin{tabular}{lr} 
CaI & 3 \\
YI 3 \\
\hdashline ScI & 3 \\
VI & 19 \\
VI & 20
\end{tabular} \\
\hline
\end{tabular}

Among C7-9 stars studied, only WZ Cas certainly, and WX Cyg probably belong to J-type stars. Both stars belong to L1 stars which show unusually strong LiI $6708 \mathrm{~A}$ line. The other $67-9$ stars in which lines of s-process elements are greatly enhanced are found not to belons to J-type stars. Hot J-type star HD 16115 is found to be certainly classified as a J-type star. It has been found that in HD 16115 abundances of s-process elements with respect to $F \theta$ are nearly normal.

III) J-type stars in the Local Group galaxies

Richer et. al.(1979,1981,1983) made photometry and spectroscopy of many carbon stars in the Large Magellanic Gloud and other Local Group galaxles. They constructed the (I, R-I) color-magnitude diagram for these carbon stars. They also took spectra of these cabon stars, and classified them on the C-classification system as defined by Yamashita. They found two kinds of J-type stars, one is of high-luminosity stars with weak $\mathrm{CN}$ bands, and the other is of low-luminosity stars with strong CN bands. We belleve that luminous $\mathrm{C}^{13}$-rich stars in the Local Group galaxies are not J-type but C7-9 stars 1ncluding CS and SC stars, and "true" J-type stars are lowluminosity stars with very strong $\mathrm{C}^{13}$ bands, and Li stars like WZ Gas.

It may be said that in all J-type stars abundances of $s$-process elements w1th respect to $F \theta$ are nearly normal.

\section{References}

Utsumi, K., 1985a, Proc. Japan Acad., 61, 193.

Utsumi, K., 1985b, Gool Stars with Excesses of Heavy Elements, ed. M. Jaschek and P. G. Keenan, p 243.

Yamashita, Y., 1972, Ann. Tokyo Astr. Obs., 2nd series, 13, no. 3. Yamashita, Y., 1975, Ann. Tokyo Astr. Obs., 2nd series, 15, no. 1. Richer, H. B., Olander, N., and Westerlund, B. E., 1979, Astrophys. J., 230, 724. Richer, H. B., 1981, Astrophys. J., 243, 744.

Richer, H. B., and Westerlund, B. E., 1983, Astrophys. J., $264,114$. 